\title{
BMJ Open Case for hospital nurse-to-patient ratio legislation in Queensland, Australia, hospitals: an observational study
}

\author{
Matthew D McHugh (D) , ${ }^{1}$ Linda H Aiken, ${ }^{1}$ Carol Windsor, ${ }^{2}$ Clint Douglas, ${ }^{2,3}$ \\ Patsy Yates (1) ${ }^{2}$
}

To cite: McHugh MD, Aiken LH, Windsor C, et al. Case for hospital nurse-to-patient ratio legislation in Queensland, Australia, hospitals: an observational study. BMJ Open 2020;10:e036264. doi:10.1136/ bmjopen-2019-036264

- Prepublication history for this paper is available online. To view these files, please visit the journal online (http://dx.doi. org/10.1136/bmjopen-2019036264).

Received 09 December 2019 Revised 27 July 2020 Accepted 28 July 2020

Check for updates

(C) Author(s) (or their employer(s)) 2020. Re-use permitted under CC BY-NC. No commercial re-use. See rights and permissions. Published by BMJ.

${ }^{1}$ School of Nursing, Center for Health Outcomes and Policy Research, University of Pennsylvania, Philadelphia, Pennsylvania, USA

${ }^{2}$ School of Nursing, Queensland University of Technology,

Brisbane, Queensland, Australia

${ }^{3}$ Metro North Hospital and

Health Service, Royal Brisbane and Women's Hospital, Herston, Queensland, Australia

Correspondence to Dr Matthew D McHugh; mchughm@nursing.upenn.edu

\section{ABSTRACT}

Objectives To determine whether there was variation in nurse staffing across hospitals in Queensland prior to implementation of nurse-to-patient ratio legislation targeting medical-surgical wards, and if so, the extent to which nurse staffing variation was associated with poor outcomes for patients and nurses.

Design Analysis of cross-sectional data derived from nurse surveys linked with admitted patient outcomes data. Setting Public hospitals in Queensland.

Participants 4372 medical-surgical nurses and 146456 patients in 68 public hospitals.

Main outcome measures 30-day mortality, quality and safety indicators, nurse outcomes including emotional exhaustion and job dissatisfaction.

Results Medical-surgical nurse-to-patient ratios before implementation of ratio legislation varied significantly across hospitals (mean 5.52 patients per nurse; $\mathrm{SD}=2.03$ ). After accounting for patient characteristics and hospital size, each additional patient per nurse was associated with $12 \%$ higher odds of 30 -day mortality $(0 \mathrm{R}=1.12 ; 95 \% \mathrm{Cl}$ 1.01 to 1.26). Each additional patient per nurse was associated with poorer outcomes for nurses including $15 \%$ higher odds of emotional exhaustion $(\mathrm{OR}=1.15 ; 95 \% \mathrm{Cl}$ 1.07 to 1.23 ) and $14 \%$ higher odds of job dissatisfaction ( $\mathrm{OR}=1.14 ; 95 \% \mathrm{Cl} 1.02$ to 1.28$)$, as well as higher odds of concerns about quality of care $(\mathrm{OR}=1.12 ; 95 \% \mathrm{Cl} 1.01$ to 1.25$)$ and patient safety $(\mathrm{OR}=1.32 ; 95 \% \mathrm{Cl} 1.11$ to 1.57$)$. Conclusions Before ratios were implemented, nurse staffing varied considerably across Queensland hospital medical-surgical wards and higher nurse workloads were associated with patient mortality, low quality of care, nurse emotional exhaustion and job dissatisfaction. The considerable variation across hospitals and the link with outcomes suggests that taking action to improve staffing levels was prudent.

\section{INTRODUCTION}

Nurses provide round-the-clock care at the hospital bedside and act as a surveillance safety net for acutely ill patients. Having enough nurses with a manageable workload is important to ensure that nurses can effectively and consistently manage patient care needs, coordinate care, preempt clinical deterioration, prevent harm and provide education for patients and families. There

\section{Strengths and limitations of this study}

- Similar study design and measures to other published international studies examining the relationship between nurse staffing and outcomes.

- Study done just before implementation of ratios policy to quantify the scope of the variation in staffing and relationship with outcomes in the state.

- Measure of staffing derived directly from staff nurses.

- Indicators of quality, safety, job dissatisfaction and emotional exhaustion from nurses as well as riskadjusted patient outcome data on mortality.

- A limitation of cross-sectional data is that we cannot confirm that observed associations are causal, although studies using longitudinal data suggest that cross-sectional results closely approximate longitudinal panel results.

is strong evidence over decades internationally showing that patients cared for in hospitals with more patients per nurse have worse outcomes including mortality, adverse events, infections and readmissions, compared with similar patients in hospitals with fewer patients per nurse. ${ }^{1-10}$

Responding to this growing evidence, the International Council of Nurses released a position statement on safe staffing in 2018, encouraging nursing organisations and governments to establish evidence-based staffing systems and policies. ${ }^{11}$ A policy intervention often discussed, but rarely implemented is setting minimum nurse-to-patient ratios. Very few places around the world have taken up such policies-California in the USA, the state of Victoria in Australia, Wales and Ireland are examples. As a result of this policy in California, the average medical or surgical unit nurse workload in California hospitals was one patient lower than in other states. Having fewer patients per nurse was associated with significantly lower patient mortality and nurse emotional exhaustion and job dissatisfaction, as well as better 
nurse-reported quality of care. ${ }^{4}$ The state of Queensland, Australia, joined this short list when, on 1 July 2016, Queensland Health established minimum nurse-topatient ratios for acute adult medical-surgical wards in 27 prescribed public hospitals across the state. The legislation requires that the average nurse-to-patient ratio on morning/afternoon shifts must be no less than 1:4 and on night shifts no less than $1: 7 .^{12}$

The purpose of this analysis was to determine the extent to which nurse-to-patient ratios varied across Queensland Health hospitals before the ratios legislation, and to evaluate the relationship between nurse-to-patient ratios and outcomes including patient mortality, quality and safety indicators and nurse job outcomes including emotional exhaustion and job dissatisfaction. While minimum ratio policies have been implemented elsewhere, this is the first baseline evaluation of the need for such legislation. A common criticism of ratio policies is that there is not empirical evidence of a problem with staffing levels specific to the jurisdiction and intervention is not needed. The results will help determine if there was an empirical basis for the legislation, and will establish a baseline level of nurse staffing and patient outcomes against which to compare the impact of the legislation in the future.

\section{METHODS}

We conducted a cross-sectional analysis of data from surveys of Queensland hospital nurses and patient outcomes data. We linked individual surgical patient outcomes data with the aggregated nurse survey data describing medical-surgical nurse-to-patient ratios using a common hospital identifier. We described facility-level medical-surgical nurse staffing levels across hospitals and evaluated whether staffing levels were associated with outcomes. The approach is based on previous research using these same methods to study the relationship between nurse-to-patient ratios and outcomes in other countries. ${ }^{3}{ }^{13}$ The theoretical foundation for this organisational-level factors approach to studying outcomes is grounded in the Quality Health Outcomes Model, which suggests that the context in which care is delivered, including the staffing adequacy, affects quality of care and patient outcomes. ${ }^{14}$

\section{Study population and data sources \\ Nurse survey}

We surveyed nurses to collect detailed information about their hospitals that is not available from any other source. We take advantage of nurses as informants of the organisational context in which care takes place because they are positioned at the bedside providing care, they are present 24 hours a day and they communicate and work directly with doctors, other providers, patients and families and hospital managers. This method of measuring organisational features of hospitals is more accurate than reports by a single 'key informant' within a hospital and is supported by the organisational research literature. ${ }^{15} \mathrm{We}$ used the nurse survey data to create measures of acute adult medical-surgical nurse-to-patient ratios, quality of care and patient safety indicators, as well as individual nurse job outcomes (ie, emotional exhaustion and job dissatisfaction).

The baseline nurse survey data were collected between May and June 2016 before implementation of ratios in July 2016. We used a modified Dillman ${ }^{16}$ approach for email survey campaigns. We sent emails and reminders to 28708 licensed nurses (all those with an available email address provided by the nurses' union, which accounted for $90 \%$ of all hospital nurses) and received responses from 8412 nurses, including 4372 nurses who self-identified as working on a medical-surgical ward, giving an overall response rate of $29 \%$. Our primary concern regarding representativeness, however, is at the hospital level; our sample of 68 public hospitals includes all Queensland public hospitals with $\geq 50$ beds and over half with $<50$ beds. The average hospital was represented by 64 respondents; thus, the preponderance of Queensland public hospitals and all prescribed for ratios are represented. We provided respondents with a list of hospitals to identify their hospital, allowing us to aggregate responses and attribute medical-surgical nurse staffing information to their hospital and link with patient outcomes data.

\section{Patient data}

To examine the relationship between adult acute medical-surgical nurse staffing and patient outcomes, we used state-based clinical patient discharge data (the Queensland Hospital Admitted Patient Data) specific to general surgery, orthopaedic and vascular surgery patients. These conditions were selected because they account for a substantial share of hospital admissions (about one-third of all adult surgical and medical patients in Queensland), most hospitals care for these patients and there are well established risk-adjustment methods. ${ }^{1718}$ This population is also consistent with other large studies evaluating the relationship between nurse staffing levels and patient outcomes internationally, which allows us to ascertain whether any evidence for this relationship in Queensland is similar or different from what has been observed outside of Australia. ${ }^{2310}$ The clinical information on patient outcomes was derived from the Queensland Hospital Admitted Patient Data, a database representing information on all inpatients in Queensland hospitals. These data were used to create the patient outcome indicator of 30-day mortality; these files also provide information on patient demographics, diagnoses and procedures (International Classification of Diseases, Tenth Revision, Australian Modification [ICD10-AM] coding), comorbidities and discharge status. The files were linked with vital statistic death records allowing us to measure the outcome of 30-day mortality. There were no missing data in the population under investigation on variables of interest for this study. 


\section{Patient and public involvement}

This study used secondary patient data from a de-identified pre-existing data set-the Queensland Hospital Admitted Patient Data. The survey of nurses was based on an established survey used in international research so that findings could be placed in the context of the broader international literature on the relationship between nurse staffing and outcomes. Thus, patients and nurses were not directly involved in the development of the research questions, variable measures or study design.

\section{Measures}

Nurse-to-patient ratios

Our primary measure of interest was the average nurseto-patient ratios on non-intensive care unit adult acute medical-surgical units (hereafter referred to as nurseto-patient ratios). To be consistent with the legislation, 'nurse' refers to both registered and enrolled nurses. By asking survey questions about how many nurses and how many patients were on the ward during the last shift, we obtain a nurse-to-patient ratio measure reflecting the average nurse-to-patient ratio for medical-surgical wards. This is consistent with the ratios legislation, which allows individual nurses to have a greater (or lesser) number of patients than the prescribed ratio so long as the ward average does not fall short during the shift. After aggregating these reports to the hospital level, this measure reflects the average nurse-to-patient ratio across all medical-surgical wards in the hospital and across shifts. This reflects the reality that over the course of a hospitalisation, patients receive care from various nurses across multiple shifts and, often, in more than one hospital unit. Patient outcomes are determined, in part, by their exposure to staffing levels over the course of their hospitalisation, which is captured by this aggregated measure. We express the ratio as the number of patients per nurse, which allows us to interpret our model results in terms of the effect of each additional patient per nurse on each outcome.

\section{Outcomes}

\section{Mortality}

We used the Queensland Hospital Admitted Patient Data to evaluate the outcome of 30-day mortality. In our mortality models, we included indicators from the Charlson comorbidity index to account for comorbidities. ${ }^{19-23}$ We also included variables indicating sex and age along with dummy variables for 78 surgical procedure types.

\section{Quality of care and patient safety}

Our survey allowed us to collect information reflecting nurses' assessments of a number of quality and safety indicators in their wards. Measures included the overall quality of care, the culture of safety, confidence that discharged patients are ready to care for themselves, confidence that management will resolve patient care concerns raised by nurses and whether nurses would recommend the hospital to family and friends in need of care. ${ }^{24}$ Evidence shows that nurse-reported quality indicators correspond closely with objective patient outcomes measures like mortality. ${ }^{2526}$

\section{Nurse outcomes}

As in prior work, ${ }^{2} 1327$ emotional exhaustion, a key feature of burnout, was measured using the Emotional Exhaustion subscale of the Maslach Burnout Inventory. $^{28}{ }^{29}$ Nurses were classified as being 'emotionally exhausted' if their score was higher than the published average for healthcare workers $(\geq 27)$. Job dissatisfaction was measured using nurses' responses to the question, 'How satisfied are you with your current job?' The 4-point Likert-type scale response options range from very satisfied to very dissatisfied. We dichotomised the measure such that nurses who reported being either very dissatisfied or a little dissatisfied were described as 'dissatisfied' and nurses reporting being moderately satisfied or very satisfied were described as 'satisfied'. ${ }^{27}$

\section{Statistical analysis}

We first described nurse-to-patient ratios across Queensland Health hospitals. We then examined the relationship between nurse-to-patient ratios and patient mortality among general, orthopaedic or vascular surgery patients. We employed a series of robust multilevel logistic regression models, accounting for clustering of patients within hospitals. We began with the unadjusted bivariate relationship between nurse staffing and mortality. Then we estimated adjusted models that included covariates to account for the various patient characteristics (eg, age, sex, comorbidities, surgical procedure) and hospital size. To evaluate the relationship between nurse-to-patient ratios and nurse job outcomes and the nurse-reported quality and safety indicators, we used robust logistic regression models, which take account of the clustering of nurses within hospitals, to estimate the odds of nurses reporting each outcome relative to an additional patient per nurse. We estimated these models before and after adjusting for hospital size and for nurse characteristics including age, sex, and years of experience.

\section{RESULTS}

Table 1 shows the characteristics of the 68 public Queensland Health hospitals with both patient data and nurse-to-patient ratio data. The average medical-surgical staffing ratios across all shifts was 5.52 patients per nurse $(\mathrm{SD}=2.03)$. For morning and afternoon shifts, the average was $5.07(\mathrm{SD}=1.85)$ patients per nurse, while for night shifts the average was $7.4(\mathrm{SD}=2.3)$ patients per nurse.

Table 2 shows the characteristics of our surgical patient population. Our analysis included 146456 general, orthopaedic and vascular surgery patients. The average mortality rate was relatively low overall (1.13\%) and is consistent with findings in Europe and the USA. ${ }^{2}$ Table 3 shows that the variation in nurse-to-patient ratios 


\begin{tabular}{|c|c|c|}
\hline & $\mathbf{N}$ & $\%$ \\
\hline \multicolumn{3}{|l|}{ Beds } \\
\hline$<50$ & 39 & $57 \%$ \\
\hline 50-99 & 8 & $12 \%$ \\
\hline $100-199$ & 5 & $7 \%$ \\
\hline $200-500$ & 11 & $16 \%$ \\
\hline$>500$ & 5 & $7 \%$ \\
\hline \multicolumn{3}{|l|}{ Medical-surgical patients per nurse } \\
\hline 4 or fewer patients per nurse & 13 & $19 \%$ \\
\hline $4 \leq 5$ patients per nurse & 26 & $38 \%$ \\
\hline $5 \leq 6$ patients per nurse & 17 & $25 \%$ \\
\hline$>6$ patients per nurse & 12 & $18 \%$ \\
\hline $\begin{array}{l}\text { Mean medical-surgical patients per } \\
\text { nurse, by shift }\end{array}$ & Mean & (SD) \\
\hline All shifts & 5.52 & $(2.03)$ \\
\hline Morning/afternoon shifts & 5.07 & $(1.85)$ \\
\hline Night shifts & 7.38 & $(2.30)$ \\
\hline
\end{tabular}

on medical-surgical wards had consequences for patients. After accounting for patient characteristics and hospital size, each additional patient per medical-surgical nurse was associated with $12 \%$ higher odds of death $(\mathrm{OR}=1.12$; $95 \%$ CI 1.01 to 1.26$)$. These results are multiplicative such that an additional two patients per nurse would be associated with $25 \%$ higher odds of death $\left(\mathrm{OR}=1.12^{2}\right.$ or 1.25$)$.

Figure 1 shows how the percentage of nurses reporting quality, safety and job outcomes varied in hospitals with different morning/afternoon staffing levels in terms of patients per nurse $(\leq 4 ; 4 \leq 5 ; 5 \leq 6$; and $>6)$. In all cases, a smaller proportion of nurses reported negative outcomes in hospitals with an average of $\leq 4$ patients per nurse. For example, only about $5 \%$ of nurses in hospitals with $\leq 4$ patients per nurse reported that quality of care is only fair or poor on their unit, while $15 \%$ of nurses in hospitals with an average of $5 \leq 6$ patients per nurse rated their hospital poorly. Twenty-four per cent of nurses in hospitals with the best staffing levels met the criteria for emotional exhaustion, while $43 \%$ of nurses in hospitals with $>6$ patients per nurse were emotionally exhausted.

\begin{tabular}{|c|c|c|}
\hline Characteristic & $\mathbf{N}$ & $\%$ \\
\hline Age (years), mean (SD) & 62.8 & (17.9) \\
\hline Male & 71616 & $48.9 \%$ \\
\hline \multicolumn{3}{|l|}{ Surgical category } \\
\hline General surgery & 44229 & $30.2 \%$ \\
\hline Orthopaedic surgery & 49062 & $33.5 \%$ \\
\hline Vascular surgery & 52165 & $36.3 \%$ \\
\hline 30-day mortality & 1654 & $1.13 \%$ \\
\hline
\end{tabular}

Table 3 Unadjusted and adjusted ORs for relationship between number of medical-surgical patients per nurse and 30-day mortality $(n=146456)$

\begin{tabular}{|c|c|c|c|c|c|c|}
\hline & \multicolumn{3}{|c|}{ Unadjusted } & \multicolumn{3}{|c|}{ Adjusted } \\
\hline & OR & $\begin{array}{l}P \\
\text { value }\end{array}$ & (95\% Cl) & OR & $\begin{array}{l}P \\
\text { value }\end{array}$ & (95\% Cl) \\
\hline $\begin{array}{l}\text { 30-day } \\
\text { mortality }\end{array}$ & 0.90 & 0.186 & $\begin{array}{l}\text { (0.78 to } \\
1.05)\end{array}$ & 1.12 & 0.048 & $\begin{array}{l}(1.01 \text { to } \\
1.26)\end{array}$ \\
\hline
\end{tabular}

Logistic regression models adjusting for patient characteristics including age, sex, 17 comorbidities (myocardial infarction, congestive heart failure; peripheral vascular disease; cerebrovascular disease; dementia; chronic obstructive pulmonary; rheumatoid disease; peptic ulcer disease; mild liver disease; diabetes; diabetes with complications; hemiplegia or paraplegia; renal disease; cancer; moderate/severe liver disease; metastatic cancer; AIDS), 78 specific surgical procedures, as well as hospital size.

Table 4 shows that in all but one instance (confidence patients can manage care after discharge), higher workloads (ie, worse nurse-to-patient ratios) were consistently associated with worse quality and safety. After accounting for individual nurse characteristics and hospital size, each additional patient per nurse was associated with $30 \%$ higher odds of a nurse not recommending the hospital to family or friends (OR=1.30; $95 \%$ CI 1.14 to 1.49$), 32 \%$ higher odds of rating patient safety at their hospital as less than excellent ( $\mathrm{OR}=1.32 ; 95 \%$ CI 1.11 to 1.57 ) and $12 \%$ higher odds of rating quality as less than excellent (OR=1.12; 95\% CI 1.01 to 1.25). Each additional patient per nurse was associated with $15 \%$ higher odds of emotional exhaustion ( $\mathrm{OR}=1.15$; $95 \%$ CI 1.07 to 1.23 ) and $14 \%$ higher odds of job dissatisfaction $(\mathrm{OR}=1.14$; 95\% CI 1.02 to 1.28). These coefficients are also multiplicative; for example, an additional two patients per nurse would be associated with $69 \%$ higher odds of not recommending the hospital to family or friends $\left(\mathrm{OR}=1.30^{2}\right.$ or 1.69).

\section{DISCUSSION}

Nurse-to-patient ratios varied considerably across Queensland Health hospitals and worse nurse-to-patient ratios were linked with patient mortality, worse quality of care and patient safety and nurse emotional exhaustion and job dissatisfaction. The finding that each additional patient per nurse was associated with increased odds of mortality is consistent with results from studies in the USA and Europe based on a similar protocol. ${ }^{23}$ Queensland is one of the few places worldwide to implement minimum nurse-to-patient ratios. While some evaluation of these policies have taken place in these other locations, this is the first baseline study of staffing ratios prior to policy implementation.

Nurse-to-patient ratios are not just important for patients; poor ratios can negatively affect nurses in terms of emotional exhaustion and job dissatisfaction, which 


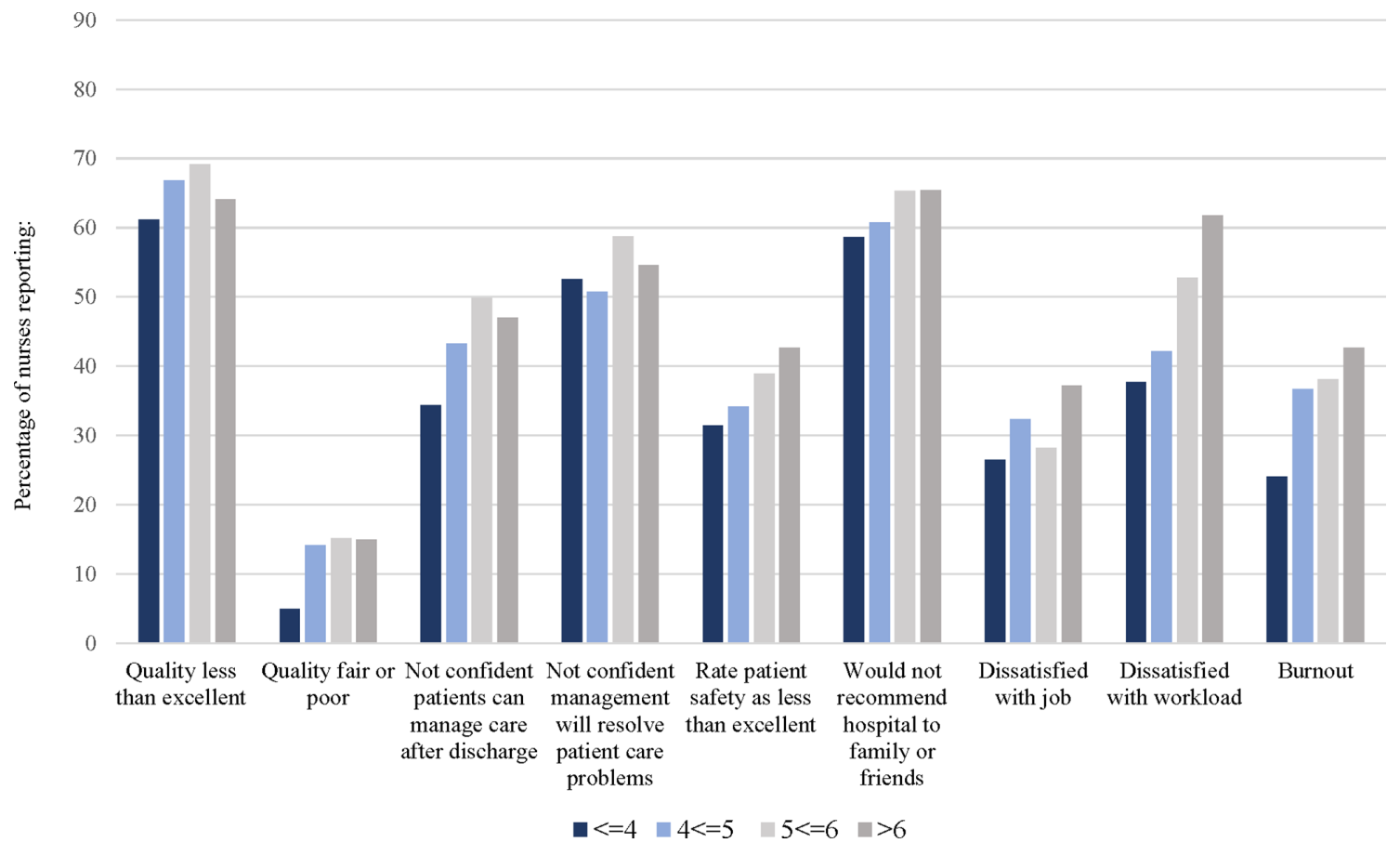

Figure 1 Percentage of nurses reporting quality, safety and job outcomes across facilities with varying nurse-to-patient ratios.

are associated with costly turnover. ${ }^{30} 31$ The National Academy of Medicine's newest landmark report, Taking Action Against Clinician Burnout: A Systems Approach to Professional Well-Being, ${ }^{32}$ highlights the central role that system factors like inadequate staffing play in the growing burnout and emotional exhaustion levels among clinicians. Our findings in Queensland are consistent with those reported in the USA and Europe regarding the link between staffing and job dissatisfaction, emotional exhaustion and concerns about quality and safety. ${ }^{2} 1324$ Studies have shown that hospitals that improved in terms of nurse staffing significantly lowered rates of emotional exhaustion among their nurses. ${ }^{33}$ These outcomes are also important indicators of hospital performance because of their relationship to patient outcomes; for example, research has shown that hospitals with many dissatisfied nurses also had higher proportions of dissatisfied patients. ${ }^{27} 34$

Nurse staffing is necessary but not sufficient to ensure good outcomes. Research suggests that hospitals with good work environments-where nurses have autonomy, opportunities for advancement, support and trust of management, excellent relationships built on professional respect with physician colleagues and active

Table 4 Unadjusted and adjusted ORs indicating the relationship between nurse staffing and quality of care and safety indicators $(\mathrm{n}=4372)$

\begin{tabular}{|c|c|c|c|c|c|c|}
\hline & \multicolumn{3}{|c|}{ Unadjusted } & \multicolumn{3}{|c|}{ Adjusted } \\
\hline & OR & $\begin{array}{l}P \\
\text { value }\end{array}$ & $(95 \% \mathrm{Cl})$ & OR & $\begin{array}{l}P \\
\text { value }\end{array}$ & $(95 \% \mathrm{Cl})$ \\
\hline \multicolumn{7}{|l|}{ Quality and safety outcomes } \\
\hline Quality less than excellent & 1.12 & 0.049 & (1.00 to 1.25$)$ & 1.12 & 0.037 & (1.01 to 1.25$)$ \\
\hline Quality fair or poor & 1.18 & 0.004 & (1.05 to 1.31$)$ & 1.17 & 0.003 & (1.05 to 1.31$)$ \\
\hline Rate patient safety as less than excellent & 1.33 & 0.002 & (0.99 to 1.52$)$ & 1.32 & 0.002 & (1.11 to 1.57$)$ \\
\hline Not confident patients can manage care after discharge & 1.09 & 0.091 & (0.99 to 1.21$)$ & 1.06 & 0.247 & (0.96 to 1.16$)$ \\
\hline Not confident management will resolve patient care problems & 1.18 & 0.034 & $(1.01$ to 1.37$)$ & 1.16 & 0.041 & (1.01 to 1.35$)$ \\
\hline Would not recommend hospital to family or friends & 1.29 & $<0.000$ & (1.12 to 1.49$)$ & 1.30 & $<0.000$ & (1.14 to 1.49 ) \\
\hline \multicolumn{7}{|l|}{ Job outcomes } \\
\hline Dissatisfied with job & 1.17 & 0.006 & (1.05 to 1.31 ) & 1.14 & 0.018 & (1.02 to 1.28$)$ \\
\hline Dissatisfied with workload & 1.37 & $<0.000$ & (1.22 to 1.53$)$ & 1.36 & $<0.000$ & (1.20 to 1.53$)$ \\
\hline Emotional exhaustion & 1.14 & $<0.000$ & (1.07 to 1.23 ) & 1.15 & $<0.000$ & (1.07 to 1.23$)$ \\
\hline
\end{tabular}

Logistic regression models adjusting for nurse characteristics (age, sex, years of experience) as well as hospital size. 
engagement in organisational decision-making-have better outcomes for nurses and patients. ${ }^{24} 33$ 35-37 The benefits of better nurse staffing are conditional on having a good work environment; thus, investing in more staff without considering the environment in which those staff work may fall short of expected improvements. ${ }^{37}$ Creating good work environments are directly within the control of management, and although they have much less associated cost than investments in more staff, they require purposeful effort. One example of an intervention aimed at improving the work environment along these domains is the Magnet hospital recognition programme. Studies show that outcomes for nurses and patients are better in Magnet hospitals, and hospitals that have pursued Magnet recognition have seen improvements beyond those seen in hospitals that have not gone through this transformation. ${ }^{38} 39$ There is only one Magnet hospital in Queensland.

A potential limitation of our study is that our data are cross-sectional. This is often suggested to imply a reduced ability to establish a conclusive causal relationship between nurse staffing levels and nurse and patient outcomes. However, we note that studies that have simultaneously considered longitudinal associations with crosssectional associations suggest that the cross-sectional findings are reasonably close to what would be observed if we were able to examine how changes in staffing over time align with changes in outcomes. ${ }^{24}$ Future research should directly employ a longitudinal design to confirm whether our cross-sectional findings are truly causative. Similarly, research determining the mechanisms through which better staffing has its impact on outcomes would be beneficial. There are some indications that by having more time to allocate to each patient when workloads are more manageable, nurses are able to provide needed care including surveillance for complications, direct engagement talking with patients and family and necessary treatments, that they would like to provide but must forego or limit due to time and resource constraints. ${ }^{40}$ Additionally, because many of our outcomes (apart from mortality) are nurse reported, further research using more outcomes from other sources would increase the robustness of the findings. We focus on nurses in medical surgical wards, aggregating to the hospital level and cannot separate specific units within that unit type, although significant variation in staffing is limited across units of the same type within the same hospital.

\section{CONCLUSION}

The International Council of Nurses' 2018 position statement on safe staffing ${ }^{11}$ highlighted the large body of international literature suggesting a consistent relationship between nurse staffing and good outcomes. Our findings in Queensland are consistent with this evidence-base and suggest that taking action to improve staffing was a reasonable policy approach that could lead to improved patient safety and quality.
Twitter Matthew D McHugh @matthewdmchugh and Linda H Aiken @LindaAiken_ Penn

Acknowledgements We would like to acknowledge Tim Cheney, Andrew Dierkes, Frances Hughes, Irene Hung, Beth Mohle, Shelley Nowlan, Douglas Sloane and Natalie Spearing for their contributions to this work.

Contributors All authors meet the criteria recommended by the International Committee of Medical Journal Editors (ICMJE). MDM, LHA, CW, CD and PY contributed to the original idea and design of the study. MDM, LHA, CW, CD and PY contributed to the collection of data. MDM conducted the data analysis. All authors contributed to the interpretation of the data and preparation of the submitted manuscript. All authors approved the submitted manuscript.

Funding This investigation was supported by Queensland Health (project NM006239/RP731123) and the National Institute of Nursing Research (NINR; R01NR014855). The funders had no role in the study design, data collection and analysis, decision to publish or preparation of the manuscript. The researchers are solely responsible for the findings and their interpretation and do not necessarily represent the views or conclusions of Queensland Health or NINR.

\section{Competing interests None declared.}

Patient and public involvement Patients and/or the public were not involved in the design, or conduct, or reporting, or dissemination plans of this research.

\section{Patient consent for publication Not required.}

Ethics approval Ethics approval was obtained from the Queensland University of Technology and the University of Pennsylvania.

Provenance and peer review Not commissioned; externally peer reviewed.

Data availability statement No data are available. The nurse survey data are not available. The patient data are from the Queensland Admitted Patient Data Collection and approval for their use can be requested directly from Queensland Health.

Open access This is an open access article distributed in accordance with the Creative Commons Attribution Non Commercial (CC BY-NC 4.0) license, which permits others to distribute, remix, adapt, build upon this work non-commercially, and license their derivative works on different terms, provided the original work is properly cited, appropriate credit is given, any changes made indicated, and the use is non-commercial. See: http://creativecommons.org/licenses/by-nc/4.0/.

\section{ORCID iDs}

Matthew D McHugh http://orcid.org/0000-0002-1263-0697

Patsy Yates http://orcid.org/0000-0001-8946-8504

\section{REFERENCES}

1 Haegdorens F, Van Bogaert P, De Meester K, et al. The impact of nurse staffing levels and nurse's education on patient mortality in medical and surgical wards: an observational multicentre study. BMC Health Serv Res 2019;19:1-9.

2 Aiken LH, Clarke SP, Sloane DM, et al. Hospital nurse staffing and patient mortality, nurse burnout, and job dissatisfaction. JAMA 2002;288:1987-93

3 Aiken LH, Sloane DM, Bruyneel L, et al. Nurse staffing and education and hospital mortality in nine European countries: a retrospective observational study. Lancet 2014;383:1824-30.

4 Aiken LH, Sloane DM, Cimiotti JP, et al. Implications of the California nurse staffing mandate for other states. Health Serv Res 2010;45:904-21.

5 Duffield C, Diers D, O’Brien-Pallas L, et al. Nursing staffing, nursing workload, the work environment and patient outcomes. Appl Nurs Res 2011;24:244-55.

6 Lasater KB, Mchugh MD. Nurse staffing and the work environment linked to readmissions among older adults following elective total hip and knee replacement. Int J Qual Health Care 2016;28:253-8.

7 Griffiths P, Maruotti A, Recio Saucedo A, et al. Nurse staffing, nursing assistants and hospital mortality: retrospective longitudinal cohort study. BMJ Qual Saf 2019;28:609-17.

8 Brooks Carthon JM, Hatfield L, Plover C, et al. Association of nurse engagement and nurse staffing on patient safety. J Nurs Care Qual 2019;34:40-6.

9 Needleman J, Buerhaus P, Pankratz VS, et al. Nurse staffing and inpatient hospital mortality. N Engl J Med 2011;364:1037-45.

10 Silber JH, Rosenbaum PR, McHugh MD, et al. Comparison of the value of nursing work environments in hospitals across different levels of patient risk. JAMA Surg 2016;151:527-36. 
11 International Council of Nurses. Evidence-based safe nurse staffing: position statement, 2018. Available: https://www.icn.ch/nursingpolicy/position-statements [Accessed 21 May 2020].

12 Palaszczuk A, Dick C. Nurse to patient ratio legislation introduced. media statement, 2015. Available: http://statements.qld.gov.au/ Statement/2015/12/1/nurse-to-patient-ratio-legislation-introducedaw

13 Aiken LH, Sermeus W, Van den Heede K, et al. Patient safety, satisfaction, and quality of hospital care: cross sectional surveys of nurses and patients in 12 countries in Europe and the United States. BMJ 2012;344:e1717.

14 Mitchell PH, Ferketich S, Jennings BM. American Academy of nursing expert panel on quality health care. quality health outcomes model. Image J Nurs Sch 1998;30:43-6.

15 Aiken M, Hage J. Organizational interdependence and IntraOrganizational structure. Am Sociol Rev 1968;33:912-30.

16 Dillman DA, Smyth JD, Christian LM. Internet, phone, mail, and mixed-mode surveys: the tailored design method. Hoboken, $\mathrm{NJ}$ : John Wiley \& Sons, 2014

17 Patel MS, Volpp KG, Small DS, et al. Association of the 2011 ACGME resident duty hour reforms with mortality and readmissions among hospitalized Medicare patients. JAMA 2014;312:2364-73.

18 Volpp KG, Rosen AK, Rosenbaum PR, et al. Mortality among hospitalized Medicare beneficiaries in the first 2 years following ACGME resident duty hour reform. JAMA 2007;298:975-83.

19 Charlson M, Szatrowski TP, Peterson J, et al. Validation of a combined comorbidity index. J Clin Epidemiol 1994;47:1245-51.

20 Li B, Evans D, Faris P, et al. Risk adjustment performance of Charlson and Elixhauser comorbidities in ICD-9 and ICD-10 administrative databases. BMC Health Serv Res 2008;8:12-19.

21 Quan H, Li B, Couris CM, et al. Updating and validating the Charlson comorbidity index and score for risk adjustment in hospital discharge abstracts using data from 6 countries. Am J Epidemiol 2011;173:676-82.

22 Quan H, Sundararajan V, Halfon P, et al. Coding algorithms for defining comorbidities in ICD-9-CM and ICD-10 administrative data. Med Care 2005;43:1130-9.

23 Sundararajan V, Henderson T, Perry C, et al. New ICD-10 version of the Charlson comorbidity index predicted in-hospital mortality. J Clin Epidemiol 2004;57:1288-94

24 Sloane DM, Smith HL, McHugh MD, et al. Effect of changes in hospital nursing resources on improvements in patient safety and quality of care: a panel study. Med Care 2018;56:1001-8.

25 McHugh MD, Stimpfel AW. Nurse reported quality of care: a measure of hospital quality. Res Nurs Health 2012;35:566-75.
26 Smeds-Alenius L, Tishelman C, Lindqvist R, et al. RN assessments of excellent quality of care and patient safety are associated with significantly lower odds of 30-day inpatient mortality: a national cross-sectional study of acute-care hospitals. Int J Nurs Stud 2016;61:117-24.

27 McHugh MD, Kutney-Lee A, Cimiotti JP, et al. Nurses' widespread job dissatisfaction, burnout, and frustration with health benefits signal problems for patient care. Health Aff 2011;30:202-10.

28 Maslach C, Jackson SE. Maslach burnout inventory manual. 2nd edn. Palo Alto, CA: Consulting Psychologists Press, 1986.

29 Maslach C, Jackson SE. Burnout in health professions: a social psychologists analysis. In: Saunders G, Suls J, eds. Social psychology of health and illness. Hillsdale, NJ: Lawrence Erlbaum Association, 1982: 227-51.

30 Gilmartin MJ. Thirty years of nursing turnover research: looking back to move forward. Med Care Res Rev 2013;70:3-28.

31 Hayes LJ, O'Brien-Pallas L, Duffield C, et al. Nurse turnover: a literature review - an update. Int J Nurs Stud 2012;49:887-905.

32 National Academies of Sciences Engineering and Medicine. Taking action against clinician burnout: a systems approach to professional well-being. Washington, DC: The National Academies Press, 2019.

33 Kutney-Lee A, Wu ES, Sloane DM, et al. Changes in hospital nurse work environments and nurse job outcomes: an analysis of panel data. Int J Nurs Stud 2013;50:195-201.

34 Vahey DC, Aiken LH, Sloane DM, et al. Nurse burnout and patient satisfaction. Med Care 2004;42:II57-66.

35 Aiken LH, Sloane DM, Barnes H, et al. Nurses' and patients appraisals show patient safety in hospitals is still deficient and recommended measures not implemented. Health Aff 2018;37:1744-51.

36 McHugh MD, Aiken LH, Eckenhoff ME, et al. Achieving Kaiser Permanente quality. Health Care Manage Rev 2016;41:178-88.

37 Aiken LH, Cimiotti JP, Sloane DM, et al. Effects of nurse staffing and nurse education on patient deaths in hospitals with different nurse work environments. Med Care 2011;49:1047-53.

38 Kutney-Lee A, Stimpfel AW, Sloane DM, Quinn L, Witkoski Stimpfel $A$, et al. Changes in patient and nurse outcomes associated with Magnet hospital recognition. Med Care 2015;53:550-7.

39 McHugh MD, Kelly LA, Smith HL, et al. Lower mortality in magnet hospitals. Med Care 2013;51:382-8.

40 Ball JE, Bruyneel L, Aiken LH, et al. Post-operative mortality, missed care and nurse staffing in nine countries: a cross-sectional study. Int J Nurs Stud 2018;78:10-15. 